\title{
Tratamento biológico de formaldeído: toxicidade residual monitorada por bioensaios com Daphnia similis
}

\author{
E.A.A. Nour ${ }^{1}$; F.P. Candello ${ }^{1}$; E.M.R. dos Santos ${ }^{2}$; A.S. Barretto ${ }^{1}$ \& L.M. Domingues ${ }^{3}$ \\ ${ }^{1}$ Laboratório de Saneamento, Departamento de Saneamento e Ambiente, Faculdade de Engenharia Civil, Arquitetura e Urbanismo, \\ Universidade Estadual de Campinas - Unicamp, Campinas - SP, Brasil. \\ ${ }^{2}$ Divisão de Vigilância Sanitária, Prefeitura Municipal de Limeira - SP, Brasil. \\ ${ }^{3}$ Laboratório Bioquimis - Análises Químicas e Biológicas, Campinas - SP, Brasil.
}

(Received May 16, 2013; Accept August 18, 2014)

\begin{abstract}
Resumo
Formaldeído é encontrado naturalmente no ambiente e pode atingir concentrações de até $4000 \mathrm{mg} \mathrm{L}^{-1} \mathrm{em}$ efluentes industriais. Embora germicida, pesquisas indicam sua possível degradação biológica em sistemas de tratamento, destacando-se os reatores com biomassa aderida e metabolismo aeróbio ou anaeróbio. Esse estudo verifica a eficiência físico-química e capacidade de redução da concentração de formaldeído adicionado a esgoto sanitário no tratamento biológico combinado (anaeróbio e aeróbio), e avalia a toxicidade aguda residual ao microcrustáceo Daphnia similis, em amostras de sistema composto por filtro anaeróbio (FA), biofiltro aerado submerso (BAS), ambos de leito fixo e fluxo ascendente, seguido de decantador secundário, nas fases: formaldeído afluente: $200 \mathrm{mg} \mathrm{L}^{-1}$ (F1: 7 bioensaios) e $400 \mathrm{mg} \mathrm{L}^{-1}$ (F2: 8 bioensaios). A eficiência de remoção de DQO e DBO foi de $93 \pm 4 \%$ e $97 \pm 2 \%$ (F1) e $93 \pm 7 \%$ e $99 \pm 1 \%$ (F2), respectivamente; a redução de formaldeído foi de $100 \%$ (F1) e $99,8 \pm 0,3 \%$ (F2). A toxicidade aguda (CE50-48h) foi de 7,22\% e 3,40\% (afluente), $>67 \%$ e $>60 \%$ (efluente FA), para F1 e F2, respectivamente. O efluente final não apresentou toxicidade aguda, comprovando a robustez do sistema combinado e a importância de tecnologias que visam à destinação adequada de resíduos e à proteção da vida aquática.

Palavras-chave: ecotoxicologia aquática, formol, microcrustáceo, sistema combinado anaeróbio-aeróbio, toxicidade aguda, tratamento de efluentes, reator biológico.
\end{abstract}

\section{INTRODUÇÃO}

A presença de formaldeído no ambiente é trivial, sendo encontrado em águas de chuva e alimentos crus, além de ser um metabólito natural do corpo humano e que se forma naturalmente nos estágios iniciais da decomposição vegetal. Mesmo certas substâncias secretadas por plantas, como os terpenos, podem gerar formaldeído a partir de reações químicas (WHO, 1989; Hohreiter \& Rigg, 2001).

A despeito de sua presença natural, o formaldeído é encontrado nas águas residuárias de empresas que utilizam sua forma comercial mais comum (composto líquido claro a $37 \%$ ) como matéria-prima em diversas atividades industriais
(ATSDR, 1999; Carvalho, 2009; INCA, 2012; Moussavi et al., 2009), podendo atingir concentrações de até $4000 \mathrm{mg} \mathrm{L}^{-1}$.

Laboratórios de universidades e centros de pesquisa que lidam com preservação de peças anatômicas de cadáveres e material biológico para estudo geram volumes consideráveis de resíduos líquidos contendo altas concentrações de formaldeído, exigindo o tratamento desse resíduo antes do lançamento em corpos d'água. Embora atue como agente germicida, destruindo moléculas de material genético e células microbianas, vários trabalhos já sinalizaram a possibilidade do formaldeído ser degradado biologicamente, empregando tecnologias de tratamento adaptadas para biodegradar efluentes com características tóxicas, dentre elas destacam-

*Corresponding author: Fernando Pena Candello; e-mail: fernando@fec.unicamp.br 
se os reatores com biomassa aderida, utilizando tanto o metabolismo aeróbio quanto o anaeróbio.

Por se tratar de um composto tóxico, a depuração biológica do formaldeído processa-se em baixas concentrações e exige uma adaptação da biomassa, o que inviabiliza o tratamento por batelada para este tipo de efluente.

Uma forma de minimizar os efeitos tóxicos de efluentes contendo formaldeído em sistemas biológicos de tratamento consiste em adicioná-los de forma controlada à entrada do sistema tratando esgoto sanitário, possibilitando uma mistura destes resíduos cuja concentração final de formaldeído seja tolerada pela biomassa existente nos reatores biológicos. No entanto, mesmo que se obtenha um efluente final cuja concentração de formaldeído seja baixa ou ausente, fazse necessário avaliar a geração de subprodutos tóxicos da degradação e remoção conjunta do formaldeído com esgoto sanitário, que possam apresentar efeitos deletérios aos organismos aquáticos presente no corpo hídrico receptor.

Por essas razões, ensaios ecotoxicológicos com organismos padronizados vem sendo empregados, permitindo estimar o efeito tóxico de determinado composto ou sua mistura na resposta destes organismos-teste e, assim, fornecer dados para avaliações de riscos ao ambiente aquático.

Para a realização de ensaios ecotoxicológicos com amostras líquidas de interesse ambiental os microcrustáceos do gênero Daphnia spp vem sendo extensivamente empregados por serem cultivados com facilidade em laboratórios bem controlados, além de possuírem homogeneidade populacional de resposta a agentes estressores, conferida pela reprodução partenogenética dos organismos. Com isso, tais ensaios fornecem indicações importantes na triagem ecotoxicológica, visando efeito preventivo dos impactos no ambiente.

O presente estudo objetiva verificar a capacidade de redução da concentração de formaldeído adicionado a esgoto sanitário durante as etapas do tratamento biológico combinado (anaeróbio e aeróbio) e avaliar a toxicidade residual ao microcrustáceo Daphnia similis, visando conciliar a proteção da vida aquática com a destinação adequada de resíduos contendo formaldeído.

$\mathrm{O}$ estudo foi realizado em duas fases, sendo estabelecida concentração nominal de $200 \mathrm{mg} \mathrm{L}^{-1}$ de formaldeído afluente na fase 1, que durou 153 dias, e $400 \mathrm{mg} \mathrm{L}^{-1}$ de formaldeído afluente na fase 2 , com duração de 259 dias.

\section{MATERIAL E MÉTODOS}

\section{Sistema combinado de tratamento}

O sistema combinado de tratamento em escala de bancada empregado nesse estudo é composto por um filtro anaeróbio (FA), um biofiltro aerado submerso (BAS), ambos de leito fixo e fluxo ascendente, seguido de um decantador secundário, localizados no Laboratório de Saneamento, do Departamento de Saneamento e Ambiente da Faculdade de Engenharia
Civil, Arquitetura e Urbanismo da Universidade Estadual de Campinas, (LABSAN/DSA/FEC/Unicamp), em Campinas/ SP, Brasil.

Ambos os reatores foram operados com Tempo de Detenção Hidráulica (TDH) de 8 horas e suas dimensões compreendem: altura: $42 \mathrm{~cm}$, diâmetro: $30 \mathrm{~cm}$, volume total: $20 \mathrm{~L}$, volume útil: 17,6 L. O meio suporte é constituído por anéis de Raschig com altura e diâmetro de $1,5 \mathrm{~cm}$. Os reatores apresentam fundos falsos perfurados, para a melhor distribuição do efluente, localizados a $4,5 \mathrm{~cm}$ do fundo. No BAS estão inseridas, na região abaixo do fundo falso, quatro pedras porosas conectadas a compressores de ar, semelhantes aos utilizados em aquários, para propiciar fornecimento de oxigênio.

Foi utilizada bomba submersa (Sarlobetter 250) para homogeneização do esgoto bruto no reservatório de alimentação, bomba peristáltica (Provitec DM 5000) para alimentação do sistema e compressores de aquário (Big Air A420) para fornecimento de ar ao BAS.

$\mathrm{Na}$ Figura 1 é apresentado o sistema de tratamento com as unidades constituintes e os pontos de amostragem para monitoramento. A unidade inicial é o reservatório de alimentação, onde se encontra o esgoto afluente bruto com formaldeído, que é bombeado ao filtro anaeróbio. O efluente do FA segue por gravidade para a entrada do biofiltro aerado submerso e o efluente decantado do BAS constitui a saída do sistema como um todo. A coleta das amostras foi realizada nos pontos: esgoto bruto contendo formaldeído (P1), efluente do filtro anaeróbio (P2) e efluente do decantador (P3).

O sistema foi alimentado com esgoto com formaldeído a uma concentração de $100 \mathrm{mg} \mathrm{L}^{-1}$ para aclimatação da biomassa por um ano, anterior ao início da operação e monitoramento referente a este estudo, sempre operando com um TDH de 16 $\mathrm{h}$, sendo $8 \mathrm{~h}$ para cada reator.

O estudo foi realizado em duas fases, sendo estabelecida concentração nominal de $200 \mathrm{mg} \mathrm{L}^{-1}$ de formaldeído afluente na fase 1, que durou 153 dias, e $400 \mathrm{mg} \mathrm{L}^{-1}$ de formaldeído afluente na fase 2, com duração de 259 dias. As concentrações foram definidas em ensaios preliminares, que demonstraram possibilidade de remoção do formaldeído sem comprometer a adaptação da biomassa do sistema de tratamento.

A duração das fases foi definida pelo desempenho do sistema, avaliado pela estabilidade relativa dos resultados dos ensaios de toxicidade e das variáveis físicas e químicas monitoradas.

\section{Esgoto sanitário com adição de formaldeído}

O esgoto gerado nas dependências da Universidade é oriundo da lavagem de pisos de salas de aula e laboratórios, utilização de sanitários e lanchonetes, possuindo características de esgoto tipicamente sanitário. As coletas foram realizadas quinzenalmente, em recipientes de polietileno (20 L), armazenados no Laboratório de Saneamento da FEC, à temperatura ambiente, para permitir a reposição diária do 


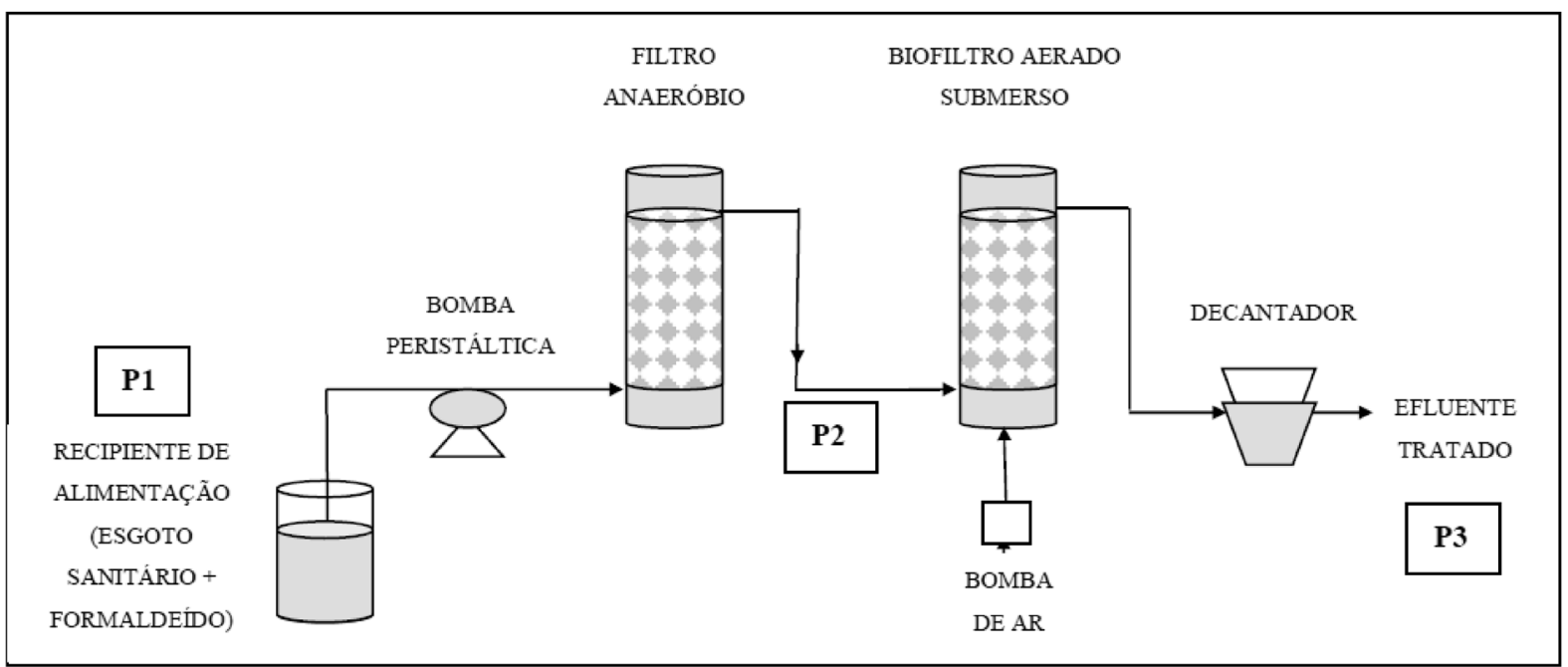

Figura 1. Sistema biológico de tratamento combinado FA/BAS.

reservatório de alimentação do sistema de tratamento com $50 \mathrm{~L}$ de esgoto bruto mais o volume necessário de soluçãoestoque de formaldeído a $37 \%$.

Antes do uso, padronizou-se cada novo lote de solução concentrada de formaldeído comercial ou formalina $(37 \%$ $\mathrm{m} / \mathrm{m}$ ), marca Synth, segundo adaptação do método do peróxido de hidrogênio para determinação de formaldeído em pesticidas (AOAC, 1995). Após a padronização, definiu-se o volume da solução a ser adicionado diariamente para se obter a concentração de $200 \mathrm{mg} \mathrm{L}^{-1}$ (fase 1) e $400 \mathrm{mg} \mathrm{L}^{-1}$ (fase 2) no esgoto afluente.

Adicionou-se solução de carbonato de sódio $\left(\mathrm{Na}_{2} \mathrm{CO}_{3}\right)$ $400 \mathrm{mg} \mathrm{L}^{-1}$ como alcalinizante, em dosagens de 0,2 a 0,7 $\mathrm{mL} \mathrm{L}^{-1}$ de esgoto bruto. A adição foi necessária para garantir a manutenção do $\mathrm{pH}$ em valores acima de 7,0 no BAS e a variação na dosagem decorreu da alcalinidade demandada pela biomassa nitrificante do reator aeróbio, monitorada pelos parâmetros alcalinidade e $\mathrm{pH}$ nas amostras do efluente final.

No reservatório de alimentação, o afluente foi mantido sob agitação contínua com o auxílio de bomba submersa, para promover homogeneização do esgoto e evitar a sedimentação dos sólidos. A caracterização física e química do esgoto afluente com e sem adição de formaldeído e alcalinizante, e das amostras dos demais pontos de monitoramento foi realizada em ambas as fases do estudo, semanalmente e no dia de início dos bioensaios.

\section{Cultivo do organismo teste}

O cultivo do microcrustáceo Daphnia similis foi realizado no Laboratório de Processos Biológicos da Universidade, sendo os organismos mantidos em cristalizadores plásticos com 4 litros de água de cultivo e 100 organismos cada, em câmara incubadora com controle de temperatura $(20,0 \pm$ $\left.0,5^{\circ} \mathrm{C}\right)$ e fotoperíodo ( $16: 8 \mathrm{~h} \mathrm{luz} /$ escuro).

A água de cultivo utilizada foi reconstituída a partir de água processada tipo I (milli-Q) com correção de dureza (45 $\left.\pm 2 \mathrm{mg} \mathrm{CaCO} \mathrm{L}^{-1}\right)$, permanecendo sob aeração constante promovida por compressor de aquário em tanque de vidro de $40 \mathrm{~L}$.

As atividades de manutenção dos cladóceros foram realizadas 3x/semana, sendo: alimentação, retirada de neonatos, filtração e troca da água de cultivo. A alimentação consistiu em fornecimento de 10 a $16 \mathrm{~mL}$ de uma suspensão de cultura monoespecífica de microalgas Pseudokirchneriella subcapitata (densidade algal 2,0 x $10^{7}$ células $\mathrm{mL}^{-1}$ ) e $2 \mathrm{~mL}$ de suplemento alimentar à base de suspensão de ração de peixes (Tetramin ) digerida e levedura dissolvida, para cada cristalizador com 100 organismos, conforme recomendações da norma técnica NBR 12713 (ABNT, 2009).

\section{Ensaios de toxicidade}

Foram realizados sete ensaios de toxicidade aguda no decorrer da fase 1 e oito ensaios ao longo da fase $2 \mathrm{com}$ amostras dos pontos de monitoramento do sistema: P1, P2, $\mathrm{P} 3$, água de cultivo de D. similis: controle (C), e esgoto bruto sem adição de formaldeído e alcalinizante: controle negativo (EBSF).

A partir das amostras coletadas, utilizou-se água de cultivo como água de diluição para o preparo de uma série de soluções-teste (concentrações em \%, definidas em ensaios preliminares). $\mathrm{Na}$ fase 1, as diluições preparadas foram: P1 $(5 \%, 7 \%, 8 \%, 10 \%$ e $20 \%), \mathrm{P} 2(50 \%, 70 \%, 80 \%, 90 \%$ e $100 \%)$, P3 $(80 \%$ e $100 \%)$. Na fase 2 , preparou-se: P1 (2\%, $3 \%, 4 \%, 6 \%$ e $8 \%), \mathrm{P} 2(10 \%, 20 \%, 40 \%, 60 \%, 80 \%$ e $100 \%)$ e P3 (100\%). Para amostras de EBSF, utilizou-se apenas a maior concentração também preparada para a série de P1, ou seja, $20 \%$ (fase 1 ) e $8 \%$ (fase 2 ).

Organismos jovens de D. similis (neonatos com idade entre 6 e 24 horas) foram expostos às soluções-teste por um período de 48 horas e mantidos em câmara incubadora a $20^{\circ} \mathrm{C}$, sem alimentação e exposição à luz (ABNT, 2009). 
Os ensaios foram realizados em quadruplicata, sendo 5 organismos para cada réplica e 20 organismos por concentração, em recipientes de polipropileno transparentes com capacidade de $100 \mathrm{~mL}$ contendo $25 \mathrm{~mL}$ da solução-teste.

Após $48 \mathrm{~h}$ foi registrado o número de indivíduos imóveis e calculadas as concentrações médias efetivas que causaram imobilidade a $50 \%$ dos organismos expostos, expressas em CE50-48h (\% v/v).

Ensaios de sensibilidade com a substância de referência cloreto de sódio $(\mathrm{NaCl})$ foram realizados mensalmente para avaliar a condição fisiológica e a adequação do lote de organismos aos ensaios de toxicidade (ABNT, 2009).

\section{ANÁLISES FÍSICAS E QUÍMICAS}

No início dos ensaios de toxicidade foram analisados os parâmetros: temperatura, $\mathrm{pH}$ ( $\mathrm{pHmetro}$ Digimed DM20), oxigênio dissolvido (OD) (oxímetro Orion 810), condutividade elétrica (condutivímetro Micronal B330) seguindo metodologias propostas por APHA (1998) e concentração de formaldeído, adaptado de NIOSH (1994), nas soluções teste preparadas a partir das amostras de P1, P2, P3, EBSF e C, sendo retiradas alíquotas antes da incubação dos organismos para permitir a realização das análises, visando avaliar possíveis interferências nas condições de ensaio.

A quantificação de formaldeído seguiu a metodologia do ácido cromotrópico, com modificações na etapa de pré-tratamento da amostra (Castagnato, 2006), utilizando zinco metálico e cobre para remoção de compostos nitrogenados oxidados.

Ao término dos ensaios, os mesmos parâmetros foram determinados apenas nos controles e nas soluções teste mais diluídas em que ocorreu o maior percentual de imobilidade dos organismos (ABNT, 2009).

Para auxiliar na avaliação da eficiência do sistema de tratamento, além das variáveis acima, os seguintes parâmetros foram monitorados, todos conforme APHA (1998) nas amostras brutas dos pontos P1, P2 e P3: alcalinidade total, demanda química de oxigênio (DQO) (digestor $\mathrm{HACH}$ e espectrofotômetro HACH DR4000), nitrogênio amoniacal $\left(\mathrm{N}-\mathrm{NH}_{3}^{+}\right.$) e demanda bioquímica de oxigênio (DBO) com frequências de realização diária, semanal, quinzenal e mensal, respectivamente.

A análise de formaldeído foi realizada também para EBSF, nos dias de início dos bioensaios, visando detectar formaldeído de ocorrência natural no esgoto sanitário.

\section{ANÁLISE DOS DADOS}

Para obtenção dos resultados de CE50-48h, com limites de confiança a 95\%, foi utilizado o Trimmed Spearman Karber Method, com auxílio do programa LC50 Programs JS Pear Test (Hamilton et al., 1977).

Utilizou-se a prova exata de Fisher com nível de significância de 0,05 , para verificar diferenças significativas na sobrevivência dos organismos teste expostos às amostras do sistema de tratamento, em relação ao grupo controle, com auxílio do programa Toxstat 3.3 (Gulley et al., 1994).

\section{RESULTADOS E DISCUSSÃO}

\section{Redução da concentração de formaldeído}

A concentração real de formaldeído afluente ao sistema foi de, em média, 203,7 $\pm 18,3 \mathrm{mg} \mathrm{L}^{-1}$ (fase 1) e 434,2 $\pm 52,0$ $\mathrm{mg} \mathrm{L}^{-1}$ (fase 2), sendo tais valores próximos à concentração nominal estipulada para cada fase: respectivamente $200 \mathrm{mg}$ $\mathrm{L}^{-1}$ e $400 \mathrm{mg} \mathrm{L}^{-1}$ de formaldeído.

Na fase 1 as eficiências médias de redução da concentração de formaldeído, em relação ao ponto 1 foram: $99 \pm 1 \%$ no ponto 2 e $100 \%$ no ponto 3. Considerando a redução de concentração do P2 para o P3, a eficiência obtida foi de 95 $\pm 11 \%$.

Este desempenho pode estar associado à adaptação da biomassa anaeróbia e aeróbia do sistema, que anteriormente já havia operado em condições semelhantes.

Com a elevação da concentração de formaldeído no esgoto afluente durante a fase 2 (de 200 para $400 \mathrm{mg} \mathrm{L}^{-1}$ ), diminuiu a eficiência do reator anaeróbio, sendo $101.6 \mathrm{mg} \mathrm{HCHO} \mathrm{L}-1$ o maior valor detectado no efluente deste reator, no $230^{\circ}$ dia do estudo. Mesmo assim, o filtro anaeróbio não registrou eficiência menor que $70 \%$ na redução de formaldeído durante toda fase 2 e alcançou eficiência média de $81,2 \pm 8,6$ \% após a adaptação da biomassa.

A maior concentração de formaldeído aplicada na fase 2 não afetou o desempenho do reator aeróbio, sendo que a maioria das amostras de $\mathrm{P} 3$ registraram concentrações de formaldeído menores que o limite de quantificação do método (LQ: $0.009 \mathrm{mg} \mathrm{HCHO} \mathrm{L}{ }^{-1}$ ), garantindo ao sistema eficiência de redução de $99,8 \pm 0,3 \%$.

Os valores das concentrações de formaldeído, nos pontos de monitoramento e em ambas as fases estão apresentados na Figura 2.

No início do estudo, a concentração de formaldeído nas amostras de P1 apresentou resultados muito abaixo da concentração nominal estabelecida, assim como relatado por Castagnato (2006) e Batista (2007), sendo uma das possíveis causas a reação imediata do composto com a matéria orgânica presente no esgoto bruto e sua volatilização.

Ensaio paralelo foi executado para estimar a degradação de formaldeído na matriz biológica ao longo de $24 \mathrm{~h}$ (intervalo de tempo para abastecimento do reservatório de alimentação do sistema), em que se obteve $10 \%$ de redução da concentração de formaldeído na reação imediata com o esgoto e 7\% de redução média nos próximos 120 minutos. Com isso, padronizou-se: a adição de $20 \%$ a mais do volume de solução de formaldeído calculado para atingir a concentração nominal, e a coleta de amostras para os bioensaios logo após o preenchimento do 


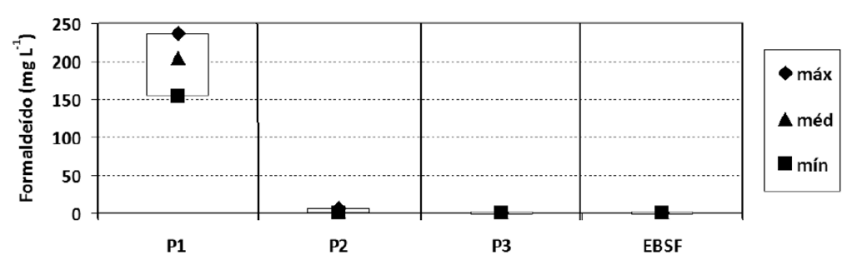

a) Fase 1: concentração nominal $200 \mathrm{mg} \mathrm{L}^{-1}$

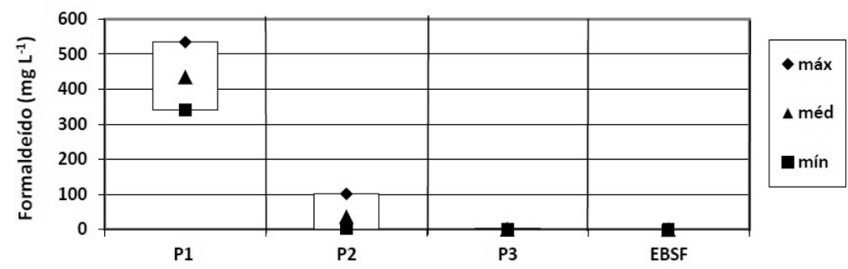

b) Fase 2: concentração nominal $400 \mathrm{mg} \mathrm{L}^{-1}$

Figura 2. Concentração real de formaldeído nos pontos de monitoramento. P1: esgoto bruto contendo formaldeído; P2: saída do reator anaeróbio; P3: saída do decantador; EBSF: esgoto bruto sem adição de formaldeído.

reservatório de alimentação. Verificou-se que, após 24 horas, a concentração de formaldeído no reservatório de alimentação é reduzida em $93 \%$, quando é realizado novo abastecimento. A dificuldade em se manter a concentração real de formaldeído afluente próxima à nominal deve-se a sua volatilização ao longo do tempo e às interações com a matéria naturalmente presente no esgoto sanitário, cujos constituintes químicos e biológicos variam quali e quantitativamente.

O EBSF apresentou baixas concentrações de formaldeído, com médias de $0,4 \pm 0,3 \mathrm{mg} \mathrm{L}^{-1}$ durante a fase 1 e $0,5 \pm 0,1$ $\mathrm{mg} \mathrm{L}^{-1}$ durante a fase 2 .

O pré-tratamento da amostra para a quantificação de formaldeído visou remover compostos nitrogenados como nitrito e nitrato, formados no tratamento aeróbio e considerados interferentes do método (Santos, 2011). Estes compostos, se não removidos, podem reagir com o ácido cromotrópico em meio ácido interferindo na leitura colorimétrica.

\section{Ensaios de toxicidade}

Os ensaios de toxicidade foram validados, obtendo-se $97,6 \%$ de mobilidade média ao final de $48 \mathrm{~h}$ de exposição dos organismos do grupo controle e os ensaios de sensibilidade resultaram em um valor médio de $\mathrm{CE}(\mathrm{I}) 50-48 \mathrm{~h}$ igual a 2,61 \pm $0,19 \mathrm{~g} \mathrm{NaCl} \mathrm{L}^{-1}$, dentro da faixa previamente estabelecida de 2,24 a $3,16 \mathrm{~g} \mathrm{NaCl} \mathrm{L}^{-1}$.

A mobilidade final média dos organismos no esgoto bruto sem adição de formaldeído (EBSF) diluído a $20 \%$ (fase 1) e a $8 \%$ (fase 2) foi de $95 \%$ no período de estudo (diferença não significativa em relação ao controle). Sendo assim, o EBSF diluído não apresentou toxicidade para $D$. similis, quando empregado nas mesmas concentrações máximas de P1, comprovando que nas diluições estudadas, o esgoto bruto não provocou, de forma isolada, toxicidade aguda a $D$. similis, embora suas características possam ter colaborado para a toxicidade obtida nos ensaios com amostras de P1, por meio da interação do formaldeído com a matriz do esgoto, e possíveis ocorrências de efeitos aditivos e/ou sinérgicos.
$\mathrm{O}$ esgoto bruto contendo formaldeído (P1) causou imobilidade a $50 \%$ dos organismos expostos em concentrações médias de 7,22\% (Fase 1) e 3,40\% (Fase 2), de acordo com a Figura 3. Tais valores de CE50-48h corresponderam, respectivamente, a concentrações nominais iniciais de formaldeído de $14,52 \mathrm{mg} \mathrm{L}^{-1}$ e $13,60 \mathrm{mg} \mathrm{L}^{-1}$, relacionando a toxicidade aguda ao formaldeído presente no esgoto e pouco dependente das características do próprio esgoto bruto.

Hohreiter \& Rigg (2001), avaliando diversos estudos de toxicidade com formaldeído, reportaram valor médio de CE50-48h de $16.4 \mathrm{mg} \mathrm{L}^{-1}$ de formaldeído para Daphnia magna e $5.8 \mathrm{mg} \mathrm{L}^{-1}$ para Daphnia pulex (Tisler \& Zagorc-Koncan, 1997), enquanto o valor médio de toxicidade aguda para o gênero Daphnia sp encontra-se em $12.9 \mathrm{mg} \mathrm{L}^{-1}$, mais próximo aos obtidos nesse estudo. Embora, entre os cladóceros desse gênero, D. magna seja a espécie mais citada na literatura sobre dados toxicológicos de formaldeído, outros pesquisadores já verificaram a equivalência de resposta de $D$. similis a diversos compostos químicos e efluentes industriais, obtendo boa correlação com D. magna (Buratini et al., 2004).

Para amostras do Ponto 2, não foi possível determinar a CE50-48h na maioria dos ensaios realizados na Fase 1 devido à redução da toxicidade e consequente melhora na qualidade do efluente após o tratamento anaeróbio, sendo que, nos ensaios em que foi possível quantificar a CE50, os valores foram superiores a $67 \%$, sugerindo baixa toxicidade (Nieto, 2000) e podem estar relacionados aos níveis de matéria orgânica no efluente ou à alteração no desempenho do sistema, já que os ensaios foram realizados com lotes diferentes de esgoto, de forma a simular as variações normais de carga em uma estação de tratamento.

Ainda em relação a P2, houve ampla variação do efeito tóxico ao longo da fase 2 (formaldeído: $400 \mathrm{mg} \mathrm{L}^{-1}$ ),

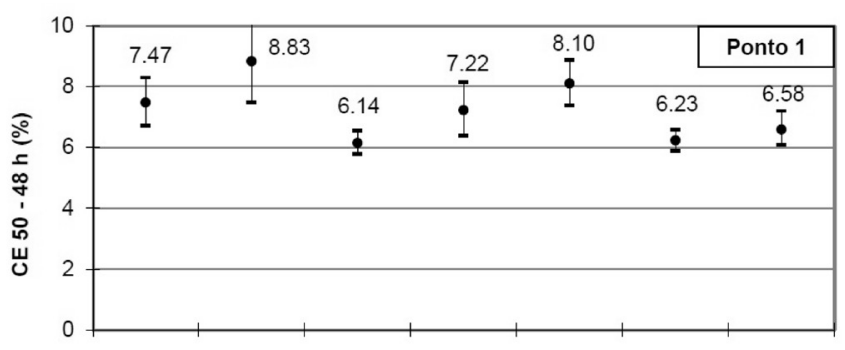

a) Fase 1 (Formaldeído $200 \mathrm{mg} \mathrm{L}^{-1}$ )

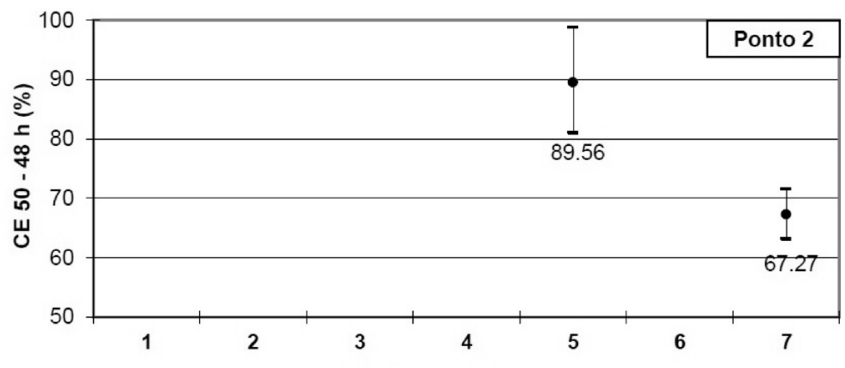

b) Fase 2 (Formaldeído $400 \mathrm{mg} \mathrm{L}^{-1}$ )

Figura 3. Concentração efetiva mediana (CE50-48h) e limites de confiança a $95 \%$, para fases 1 e 2 . 
provavelmente devido à desestabilização do sistema com o aumento de concentração do formaldeído. Nos primeiros ensaios, observa-se aumento progressivo da toxicidade pelos valores decrescentes de CE50/48h e, a partir do $6^{\circ}$ ensaio, a elevação dos valores de CE50 para valores acima de $60 \%$ indica recuperação no desempenho do reator anaeróbio.

Ensaios com amostras de P3, que representa o efluente final do sistema combinado, resultaram em ausência de toxicidade aguda, com média de sobrevivência de 96.4\%, diferença essa não significativa em relação ao controle ( $\mathrm{p}>$ 0.05 ), confirmando a elevada eficiência do sistema proposto para tratar esgoto com adição de formaldeído, reduzindo sua concentração e toxicidade, nas condições empregadas.

A despeito da volatilidade do formaldeído, foi possível monitorar com reprodutibilidade a dinâmica de sua concentração ao longo do sistema combinado de tratamento, a partir do ensaio agudo de toxicidade, que apresenta tempo curto de exposição do organismo teste, em comparação ao seu ciclo de vida.

\section{Variáveis físicas e químicas e desempenho do sistema}

Na Fase 1, a matéria orgânica de entrada do sistema (quantificada indiretamente sob a forma de DQO) apresentou valor médio de $625 \pm 139 \mathrm{mg} \mathrm{O}_{2} \mathrm{~L}^{-1}$, sendo que a eficiência de remoção foi de $73 \pm 12 \%$ para o $\mathrm{P} 2$ e $93 \pm 4 \%$ para o $\mathrm{P} 3$, enquanto a DBO foi removida a $69 \pm 27 \%$ e $97 \pm 2 \%$, respectivamente.

Na Fase 2, a DQO média de entrada foi de $1001 \pm 399$ mg $\mathrm{O}_{2} \mathrm{~L}^{-1}$, sendo que os valores de eficiência de redução foram de $60 \pm 24 \%$ e $93 \pm 7 \%$ respectivamente, para $\mathrm{P} 2$ e P3 comparados a P1, mantendo praticamente a mesma eficiência global da fase anterior. A DBO foi removida a $66 \pm 12 \%$ e $99 \pm 1 \%$, respectivamente, com o FA sendo menos eficiente nessa fase. Mesmo assim, após o tratamento pelo BAS e decantador, conferiu-se DBO média de $10 \pm 5 \mathrm{mg} \mathrm{O}_{2} \mathrm{~L}^{-1}$ ao efluente P3.

Considerando as condições e os padrões de lançamento de efluentes em corpos hídricos no Estado de São Paulo (Lei 997/76 - art.18), sendo o limite de lançamento de $60 \mathrm{mg} \mathrm{\textrm {O } _ { 2 }}$ $\mathrm{L}^{-1}$, ou remoção de pelo menos $80 \%$ de DBO, e em esfera federal (MMA, 2011) a exigência de remoção mínima de 60 $\%$ de DBO, o sistema combinado manteve o desempenho atendendo ambas as legislações.

A concentração média de $\mathrm{OD}$ em $\mathrm{P} 3$, de $6,1 \pm 0,7 \mathrm{mg} \mathrm{O}$ $\mathrm{L}^{-1}$ não foi limitante para a atividade da biomassa aeróbia na fase 1. Ocorreram oscilações nos valores a partir do $101^{\circ}$ dia de operação devido à presença de elevadas concentrações de nitrogênio amoniacal $\left(\mathrm{N}^{-\mathrm{NH}_{3}}\right)$ em P1 e P2. A análise de $\mathrm{N}_{-} \mathrm{NH}_{3}$ visou identificar níveis que porventura poderiam conferir toxicidade aos bioensaios. Considerando a concentração média de amônia detectada nas amostras sem diluição, a toxicidade em P2 (efluente anaeróbio), poderia ser devida a amônia. A presença de amônia combinada com condições de hipóxia causa sinergia que pode intensificar o efeito tóxico, embora crônico, aos cladóceros (Lyu et al., 2013). Para as amostras de P1 e P3, devido ao fato de serem, respectivamente, bastante diluídas e aeróbias, os níveis de amônia não contribuiriam com toxicidade aguda ao organismo-teste, por estarem distantes do valor de CL50-48h de $69 \mathrm{mg} \mathrm{N}-\mathrm{NH}_{3} \mathrm{~L}^{-1}$ para Daphnia magna, descrito por Zhao et al. (2011).

$\mathrm{Na}$ fase 2, os valores de OD variaram muito em todas as etapas do tratamento, mas foram menores que na fase anterior, o que pode ser devido ao maior período de adaptação da biomassa à nova concentração de formaldeído aplicada.

Em relação ao $\mathrm{pH}$, não houve variações significativas com a adição contínua de $\mathrm{Na}_{2} \mathrm{CO}_{3}$ afluente ao sistema. $\mathrm{O}$ valor médio de $\mathrm{pH}$ obtido para $\mathrm{P} 1$ foi de $8,1 \pm 0,4$ na fase 1 , acima da faixa usual para esgoto sanitário bruto de $\mathrm{pH} \quad 6,5$ a 7,5 (Jordão \& Pessoa, 2009), no entanto, pelo desempenho do sistema indicado nas demais variáveis analisadas, este valor não foi prejudicial. Nos demais pontos de amostragem, o pH manteve-se em torno de 7 , faixa considerada ótima para a atividade da biomassa (Tabela 1).

Amostras de esgoto bruto ou provenientes de etapas de sistemas de tratamento geralmente apresentam parâmetros cujos valores encontram-se fora da faixa requerida para a validação dos ensaios biológicos, quais sejam: $\mathrm{pH}$, temperatura, condutividade elétrica e OD específicos para o organismo-teste que se deseja avaliar.

No presente estudo, a diluição das amostras brutas em água de cultivo foi fundamental para propiciar condições ambientais mínimas de sobrevivência para os organismos, já

Tabela 1. Valores médios ( \pm DP) das variáveis físicas e químicas monitoradas durante o período experimental nos pontos de monitoramento

\begin{tabular}{|c|c|c|c|c|c|c|}
\hline \multirow[t]{2}{*}{ Variável } & \multicolumn{3}{|c|}{ Fase 1} & \multicolumn{3}{|c|}{ Fase 2} \\
\hline & $\mathrm{P} 1$ & $\mathrm{P} 2$ & P3 & $\mathrm{P} 1$ & P2 & P3 \\
\hline $\mathrm{pH}$ & $\begin{array}{c}8.1 \\
( \pm 0.4)\end{array}$ & $\begin{array}{c}7.2 \\
( \pm 0.2)\end{array}$ & $\begin{array}{c}7.3 \\
( \pm 0.3)\end{array}$ & $\begin{array}{c}7.6 \\
( \pm 0.4)\end{array}$ & $\begin{array}{c}6.8 \\
( \pm 0.2)\end{array}$ & $\begin{array}{c}7.4 \\
( \pm 0.3)\end{array}$ \\
\hline $\begin{array}{l}\text { OD } \\
\left(\mathrm{mg} \mathrm{L}^{-1}\right)\end{array}$ & $\begin{array}{c}1.0 \\
( \pm 0.5)\end{array}$ & $\begin{array}{c}1.5 \pm \\
( \pm 1.2)\end{array}$ & $\begin{array}{c}6.1 \\
( \pm 0.7)\end{array}$ & $\begin{array}{c}1.2 \\
( \pm 0.6)\end{array}$ & $\begin{array}{c}0.6 \\
( \pm 0.6)\end{array}$ & $\begin{array}{c}5.6 \\
( \pm .1)\end{array}$ \\
\hline $\begin{array}{l}\text { Condutividade Elétrica } \\
(\mu \mathrm{S} \mathrm{cm}-1)\end{array}$ & $\begin{array}{c}1018 \\
( \pm 252)\end{array}$ & $\begin{array}{c}1053 \\
( \pm 215)\end{array}$ & $\begin{array}{c}785 \\
( \pm 161)\end{array}$ & $\begin{array}{c}1044 \\
( \pm 206)\end{array}$ & $\begin{array}{c}1047 \\
( \pm 203)\end{array}$ & $\begin{array}{c}785 \\
( \pm 141)\end{array}$ \\
\hline $\begin{array}{l}\text { Formaldeído } \\
\left(\mathrm{mg} \mathrm{L}^{-1}\right)\end{array}$ & $\begin{array}{c}203.7 \\
( \pm 18.3)\end{array}$ & $\begin{array}{c}2.4 \\
( \pm 1.9)\end{array}$ & $\begin{array}{c}0.1 \\
( \pm 0.1)\end{array}$ & $\begin{array}{c}434.2 \\
( \pm 52.0)\end{array}$ & $\begin{array}{c}36.5 \\
( \pm 33.6)\end{array}$ & $\begin{array}{c}2.6 \\
( \pm 0.6)\end{array}$ \\
\hline $\begin{array}{l}\text { Alcalinidade Total } \\
\left(\mathrm{mg} \mathrm{CaCO}_{3} \mathrm{~L}^{-1}\right)\end{array}$ & $\begin{array}{c}378 \\
( \pm 87)\end{array}$ & $\begin{array}{c}388 \\
( \pm 78)\end{array}$ & $\begin{array}{c}97 \\
( \pm 61)\end{array}$ & $\begin{array}{c}347 \\
( \pm 89)\end{array}$ & $\begin{array}{c}357 \\
( \pm 86)\end{array}$ & $\begin{array}{c}135 \\
( \pm 80)\end{array}$ \\
\hline $\begin{array}{l}\text { DQO } \\
\left(\mathrm{mg} \mathrm{O}_{2} \mathrm{~L}^{-1}\right)\end{array}$ & $\begin{array}{c}625 \\
( \pm 139)\end{array}$ & $\begin{array}{c}167 \\
( \pm 98)\end{array}$ & $\begin{array}{c}41 \\
( \pm 25)\end{array}$ & $\begin{array}{c}1001 \\
( \pm 399)\end{array}$ & $\begin{array}{c}386 \\
( \pm 268)\end{array}$ & $\begin{array}{c}62 \\
( \pm 28)\end{array}$ \\
\hline $\begin{array}{l}\text { DBO } \\
\left(\mathrm{mg} \mathrm{O}_{2} \mathrm{~L}^{-1}\right)\end{array}$ & $\begin{array}{c}307 \\
( \pm 37)\end{array}$ & $\begin{array}{c}99 \\
( \pm 84)\end{array}$ & $\begin{array}{c}10 \\
( \pm 9)\end{array}$ & $\begin{array}{c}694 \\
( \pm 265)\end{array}$ & $\begin{array}{c}240 \\
( \pm 138)\end{array}$ & $\begin{array}{c}10 \\
( \pm 5)\end{array}$ \\
\hline $\begin{array}{l}\mathrm{N}-\mathrm{NH}_{3}^{+} \\
\left(\mathrm{mg} \mathrm{L}^{-1}\right)\end{array}$ & $\begin{array}{c}50 \\
( \pm 22)\end{array}$ & $\begin{array}{c}45 \\
( \pm 13)\end{array}$ & $\begin{array}{c}3 \\
( \pm 4)\end{array}$ & $\begin{array}{c}50 \\
( \pm 20)\end{array}$ & $\begin{array}{c}54 \\
( \pm 21)\end{array}$ & $\begin{array}{c}12 \\
( \pm 17)\end{array}$ \\
\hline
\end{tabular}


que tais parâmetros estão entre os principais fatores abióticos que podem interferir nos resultados dos ensaios (Zagatto \& Bertoletti, 2008).

$\mathrm{Na}$ Tabela 2 são apresentados os valores médios, mínimos e máximos das variáveis físicas e químicas, no início e fim dos ensaios para todos os pontos de monitoramento. O parâmetro temperatura não foi tabelado pois os recipientes com as respectivas soluções teste foram aclimatados a $20 \pm 1^{\circ} \mathrm{C}$ por 30 minutos antes da transferência dos organismos e esse valor médio se manteve ao final dos ensaios em todas as soluções teste.

Os controles apresentaram parâmetros iniciais e finais dentro da faixa esperada para o cultivo, no entanto, concentrações muito baixas de formaldeído foram detectadas e podem ser devidas às limitações na metodologia de análise (NIOSH, 1994) e possíveis interferências das substâncias utilizadas para a correção da dureza da água de cultivo dos organismos.

O EBSF não apresentou concentrações de formaldeído detectáveis pelo método, devido às altas diluições das soluções-teste, embora análises nas amostras brutas resultaram em concentrações de até $0,8 \mathrm{mg} \mathrm{HCHO} \mathrm{L}^{-1}$.
$\mathrm{O}$ valor de $\mathrm{pH}$ dos pontos e ao longo dos ensaios apresentou pouca variação, sendo o valor médio mínimo de 7,3 no início dos ensaios e a média máxima de 8,3 ao final. As soluções teste não apresentaram valor inicial ou final $\mathrm{de} \mathrm{pH}$ fora da faixa 5,0 a 9,0 e OD abaixo de $2,0 \mathrm{mg} \mathrm{L}^{-1}$, como recomendado em ABNT (2009), exceto para um ensaio na fase 1, com amostra P2 sem diluição, cujo valor inicial de OD foi menor que $1,0 \mathrm{mg} \mathrm{L}^{-1} \mathrm{e}$, mesmo assim, não foi observada toxicidade aguda para o organismo teste. Em média, os valores de OD aumentaram durante os ensaios quando os valores iniciais estavam bem abaixo do valor de saturação.

A condutividade elétrica (CEL) apresentou elevada variação entre os pontos, obtendo-se altos valores, com a média mínima de $171 \mu \mathrm{S} \mathrm{cm}^{-1}$ no início do ensaio para o P1 e as médias máximas finais de $817 \mu \mathrm{S} \mathrm{cm} \mathrm{cm}^{-1}$ e $936 \mu \mathrm{S} \mathrm{cm} \mathrm{cm}^{-1}$ para $\mathrm{P} 2$ e P3, respectivamente. Entre o início e fim dos ensaios para um mesmo ponto, a variação foi pequena, ora crescente, ora decrescente, provavelmente devido à interação da solução teste com a atividade metabólica dos organismos e suas excretas.

Tabela 2. Valores médios, médias mínimas e máximas das variáveis físicas e químicas analisadas nas soluções teste, no início (0h) e término (48h) dos ensaios de toxicidade.

\begin{tabular}{|c|c|c|c|c|c|c|c|c|c|c|}
\hline \multirow[b]{3}{*}{$\mathrm{pH}$} & \multicolumn{2}{|c|}{ P1 } & \multicolumn{2}{|c|}{$\mathrm{P} 2$} & \multicolumn{2}{|c|}{ P3 } & \multicolumn{2}{|c|}{ EBSF } & \multicolumn{2}{|c|}{$\mathrm{C}$} \\
\hline & \multicolumn{10}{|c|}{ Fase 1} \\
\hline & $\mathrm{Oh}$ & $48 \mathrm{~h}$ & Oh & $48 \mathrm{~h}$ & $\mathrm{Oh}$ & $48 \mathrm{~h}$ & $\mathrm{Oh}$ & $48 \mathrm{~h}$ & Oh & $48 h$ \\
\hline méd & 7.9 & 7.7 & 7.3 & 8.4 & 7.4 & 8.2 & 7.6 & 8.0 & 7.7 & 8.2 \\
\hline mín & 7.7 & 7.5 & 7.0 & 8.3 & 7.0 & 7.9 & 7.4 & 7.2 & 7.5 & 7.9 \\
\hline máx & 8.2 & 8.1 & 7.7 & 8.5 & 7.7 & 8.3 & 7.8 & 8.3 & 7.9 & 8.5 \\
\hline \multicolumn{11}{|c|}{$\begin{array}{l}\text { Condutiv. Elétrica } \\
\left(\mu \mathrm{S} \mathrm{cm}^{-1}\right)\end{array}$} \\
\hline méd & 233 & 256 & 908 & 764 & 691 & 735 & 241 & 241 & 172 & 198 \\
\hline mín & 182 & 195 & 752 & 617 & 430 & 503 & 161 & 164 & 128 & 144 \\
\hline máx & 286 & 302 & 1011 & 817 & 808 & 936 & 336 & 320 & 210 & 257 \\
\hline \multicolumn{11}{|c|}{$\mathrm{OD}\left(\mathrm{mg} \mathrm{L}^{-1}\right)$} \\
\hline méd & 7.3 & 7.5 & 3.7 & 7.3 & 6.7 & 7.4 & 6.4 & 7.4 & 7.0 & 7.4 \\
\hline mín & 6.9 & 7.0 & 0.8 & 6.6 & 6.2 & 6.2 & 4.3 & 5.8 & 4.5 & 5.8 \\
\hline máx & 7.9 & 7.9 & 5.4 & 7.7 & 7.3 & 7.9 & 7.8 & 7.9 & 8.3 & 8.0 \\
\hline \multicolumn{11}{|c|}{$\begin{array}{l}\text { Formaldeído } \\
\left(\mathrm{mg} \mathrm{L}^{-1}\right)\end{array}$} \\
\hline méd & 16.8 & 0.27 & 1.16 & 0.21 & 0.03 & $*$ & $*$ & $*$ & 0.05 & 0.08 \\
\hline mín & 15.0 & 0.14 & $*$ & $*$ & $*$ & $*$ & $*$ & $*$ & $*$ & $*$ \\
\hline \multirow[t]{2}{*}{ máx } & 19.9 & 0.48 & 2.35 & 0.61 & 0.21 & $*$ & $*$ & $*$ & 0.18 & 0.36 \\
\hline & \multicolumn{10}{|c|}{ Fase 2} \\
\hline$\overline{\mathrm{pH}}$ & Oh & $48 \mathrm{~h}$ & $0 \mathrm{~h}$ & $48 \mathrm{~h}$ & $\mathrm{Oh}$ & $48 \mathrm{~h}$ & $0 \mathrm{~h}$ & $48 \mathrm{~h}$ & $\mathrm{Oh}$ & $48 \mathrm{~h}$ \\
\hline méd & 7.5 & 7.3 & 7.2 & 8.0 & 7.6 & 8.0 & 7.5 & 7.7 & 7.7 & 8.2 \\
\hline mín & 7.1 & 6.9 & 7.1 & 7.7 & 7.2 & 7.3 & 7.4 & 7.1 & 7.3 & 7.9 \\
\hline máx & 7.8 & 7.7 & 7.4 & 8.4 & 7.9 & 8.4 & 7.8 & 8.3 & 7.8 & 8.0 \\
\hline \multicolumn{11}{|c|}{$\begin{array}{l}\text { Condutiv. Elétrica } \\
\left(\mu \mathrm{S} \mathrm{cm}^{-1}\right)\end{array}$} \\
\hline méd & 208 & 197 & 577 & 496 & 711 & 675 & 217 & 228 & 176 & 166 \\
\hline mín & 171 & 168 & 419 & 386 & 585 & 570 & 173 & 192 & 149 & 145 \\
\hline máx & 275 & 230 & 829 & 673 & 886 & 845 & 306 & 302 & 273 & 201 \\
\hline \multicolumn{11}{|c|}{$\mathrm{OD}\left(\mathrm{mg} \mathrm{L}^{-1}\right)$} \\
\hline méd & 7.6 & 7.5 & 4.4 & 7.3 & 6.6 & 7.8 & 7.0 & 7.8 & 7.0 & 7.8 \\
\hline mín & 7.4 & 7.2 & 3.4 & 6.7 & 6.1 & 7.6 & 5.7 & 7.6 & 5.7 & 7.6 \\
\hline máx & 7.8 & 7.8 & 5.8 & 7.9 & 7.3 & 7.9 & 7.4 & 8.1 & 7.4 & 8.1 \\
\hline \multicolumn{11}{|c|}{ Formaldeído $\left(\mathrm{mg} \mathrm{L}^{-1}\right)$} \\
\hline méd & 17.0 & 1.7 & 17.6 & 0.6 & 0.4 & 0.2 & * & $*$ & 0.1 & 0.1 \\
\hline min & 15.0 & 0.1 & 2.2 & 0.4 & $*$ & $*$ & * & $*$ & $*$ & $*$ \\
\hline max & 19.2 & 6.0 & 37.5 & 0.9 & 2.4 & 1.4 & $*$ & $*$ & 0.2 & 0.2 \\
\hline
\end{tabular}

* Menor que o limite de quantificação do método: L.Q. $=0.009 \mathrm{mg}$ formaldeído $\mathrm{L}^{-1}$. 
Embora valores elevados de CEL como apresentados em P2 e P3 não sejam adequados em água para cultivo de dafnídeos, por não satisfazerem condições ótimas de criação, a ocorrência em ensaios de toxicidade aguda pode ser tolerada por não provocar estresse fisiológico aos organismos devido à curta duração dos ensaios, consistindo este um desafio inerente à montagem de experimentos que submetem amostras reais de interesse ambiental (e não apenas substâncias teste puras diluídas em água de cultivo) aos ensaios ecotoxicológicos.

O gênero Daphnia sp é originalmente holártico, com seus organismos sendo encontrados em ambientes de águadoce, cuja salinidade e CEL geralmente são menores que $500 \mathrm{mg} \mathrm{L}^{-1}$ e $500 \mu \mathrm{S} \mathrm{cm}^{-1}$, respectivamente (Gómez-Díaz \& Martínez-Jerónimo, 2009), mas D. similis já foi encontrada em ambientes naturais com CEL entre 91 a $1260 \mu \mathrm{S} \mathrm{cm}$, embora a maioria dos ambientes apresentava CEL menor que $1000 \mu \mathrm{S} \mathrm{cm}^{-1}$ (Forró, 1994).

A concentração de formaldeído nas soluções teste decaiu durante os ensaios, obtendo-se no máximo $10 \%$ da concentração inicial após $48 \mathrm{~h}$ de exposição, devido ao caráter volátil do mesmo. Os valores médios máximos variaram de $19,9 \mathrm{mg} \mathrm{L}^{-1}$ no início ao valor mínimo $<0,009 \mathrm{mg} \mathrm{L}^{-1}$ (limite de quantificação do método) no término, para $\mathrm{P} 1$ e $\mathrm{P} 3$, respectivamente.

\section{CONCLUSÃO}

O esgoto bruto contendo formaldeído foi tóxico (CE50-48h $<10 \%$ ) para o organismo Daphnia similis e esta toxicidade elevou-se com o aumento da concentração de formaldeído afluente.

$\mathrm{Na}$ fase 1, o efluente gerado pelo filtro anaeróbio (P2) apresentou baixa toxicidade a $D$. similis, com valor de CE50$48 \mathrm{~h}$ de $67,27 \%$ a não tóxico (ausência de toxicidade aguda). $\mathrm{Na}$ fase 2, no entanto, o FA foi bastante sensível ao aumento na concentração de formaldeído, sendo necessário um período de adaptação da biomassa anaeróbia para assimilar o aumento da carga orgânica e da toxicidade do formaldeído, sendo que a toxicidade para $\mathrm{P} 2$ variou de $17,17 \%$ a $87,52 \%$.

Verificou-se que o FA foi responsável pela maior parte do tratamento e redução da toxicidade do formaldeído, cabendo ao conjunto BAS + decantador a realização do póstratamento, melhorando as qualidades do efluente e reduzindo a concentração do formaldeído.

Em ambas as fases do estudo, o efluente final (P3) do sistema combinado não foi tóxico para a espécie $D$. similis, comprovando a robustez do sistema combinado para tratamento de substâncias de caráter tóxico como o formaldeído.

A utilização dos ensaios de toxicidade como forma de monitoramento comprovou que mesmo a caracterização do sistema utilizando variáveis físicas e químicas que indicam elevada eficiência no tratamento não representa o real efeito do lançamento do efluente no ambiente.

Estudos futuros com concentrações mais elevadas de formaldeído e monitoramento com espécies de diferentes posições na cadeia trófica podem fornecer dados que ajudem a aperfeiçoar tecnologias para o descarte de substâncias potencialmente tóxicas de forma ambientalmente responsável.

\section{AGRADECIMENTOS}

À equipe do Labsan/FEC/DSA/Unicamp e ao CNPq pelo financiamento do projeto.

\section{REFERÊNCIAS}

APHA - American Public Health Association, 1998, Standard Methods for the Examination of Water and Wastewater, 20th ed. Washington, D.C.

ABNT - Associação Brasileira de Normas Técnicas, 2009, NBR 12713. Ecotoxicologia aquática: toxicidade aguda - método de ensaio com Daphnia spp (Crustacea: Cladocera), Rio de janeiro, $23 \mathrm{p}$.

AOAC - Association of Official Analytical Chemists, 1995, Official method 898.01 - Formaldehyde in pesticide formulations, hydrogen peroxide method. In: Official methods of analysis of AOAC international, 16th ed. Arlington. In: AOAC International 2, $99 \mathrm{p}$.

ATSDR - Agency for Toxic Substances and Disease Registry, 1999, Toxicological profile for formaldehyde (final Report). NTIS Accession No. PB99-166654, Atlanta, GA, 451 p.

BATISTA, V. M., 2007, Tratamento de esgoto sanitário contendo formaldeído utilizando filtro anaeróbio seguido de biofiltro aerado submerso: desempenho e avaliação da biomassa. (Dissertação de mestrado). Faculdade de Engenharia Civil, Arquitetura e Urbanismo, Universidade Estadual de Campinas, Campinas, SP, Brasil.

BURATINI, S. V., BERTOLETTI \& E., ZAGATTO, P. A., 2004. Evaluation of Daphnia similis as a test species in ecotoxicological assays. Bull. Environmental Contamination and Toxicology, 73: 878-882. http://dx.doi.org/10.1007/s00128-004-0508-8

CARVALHO, K. S., 2009, Influência do formol utilizado para conservação de cadáveres na obtenção de DNA nuclear em tecido muscular. Dissertação de mestrado. Faculdade de Odontologia de Piracicaba, Universidade Estadual de Campinas. Piracicaba, SP, Brasil.

CASTAGNATO, R., 2006, Tratabilidade de esgoto sanitário contendo formaldeído em um sistema combinado filtro anaeróbio - biofiltro aerado submerso. Dissertação de mestrado. Faculdade de Engenharia Civil, Arquitetura e Urbanismo, Universidade de Campinas, Campinas, SP, Brasil.

FORRÓ, L., 1994, Distribution and occurrence of Daphnia atkinsoni Baird, 1859 and Daphnia similis Claus, 1876 (Crustacea, Anomopoda) in Hungary. Miscnea Zool. Hung. 9: 83-88.

GÓMEZ-DÍAZ, M. P. \& MARTÍNEZ-JERÓNIMO, F. 2009, Modification of the acute toxic response of Daphnia magna Straus 1820 to $\mathrm{Cr}(\mathrm{VI})$ by the effect of varying saline concentrations $(\mathrm{NaCl})$. Ecotoxicology, 18: 81-86. http://dx.doi.org/10.1007/ s10646-008-0260-7

GULLEY, D.D., BOELTER, A.M. \& BERGMAN, H.L., 1994, Toxstat 3.4 Computer Program.

HAMILTON, M., RUSSO, R.C. \& THURSTON, R.V., 1977, Trimmed Spearman-Karber method for estimating median lethal concentrations in toxicity bioassays. Environ. Sci. Technol., 11: 714-719. http://dx.doi.org/10.1021/es60130a004

HOHREITER, D. W. \& RIGG, D. K., 2001, Derivation of ambient water quality criteria for formaldehyde. Chemosphere, 45: 471- 
486. http://dx.doi.org/10.1016/S0045-6535(01)00061-3

INCA - Instituto Nacional de Câncer, 2012, Disponível em: <http:// www.inca.gov.br/conteudo_view.asp?id=795> Acesso em: 05/06/2012.

JORDÃO, E. P. \& PESSOA, C. A., 2009, Tratamento de esgotos domésticos - $5^{\mathrm{a}}$ ed, ABES, Rio de Janeiro.

LYU, K., CAO, H., CHEN, R., WANG, Q., YANG, Z., 2013, Combined effects of hypoxia and ammonia to Daphnia similis estimated with life-history traits. Environ Sci Pollut Res, 20: 5379-5387. http://dx.doi.org/10.1007/s11356-013-1555-7

MMA - Ministério do Meio Ambiente, 2011, Conselho Nacional do Meio Ambiente - CONAMA - Resolução no 430 - Dispõe sobre as condições e padrões de lançamento de efluentes, complementa e altera a Resolução no 357, de 17 de março de 2005, do CONAMA. Diário Oficial da União, Brasília, 16 de maio de 2011a, 8 p.

MOUSSAVI, G.; YAZDANBAKHSHB, A. \& HEIDARIZADA, M., 2009, The removal of formaldehyde from concentrated synthetic wastewater using $\mathrm{O}_{3} / \mathrm{MgO} / \mathrm{H}_{2} \mathrm{O}_{2}$ process integrated with the biological treatment. Journal of Hazardous Materials 171, 907-913. http://dx.doi.org/10.1016/j.jhazmat.2009.06.090

NIETO, R., 2000, Caracterização ecotoxicológica de efluentes líquidos industriais - ferramenta para ações de controle da poluição das águas. In: XXVII Congresso de Engenharia Sanitária e Ambiental, Porto Alegre.

NIOSH - National Institute for Occupational Safety and Health, 1994, Manual of analytical methods (NMAN): method 3500(2) - formaldehyde. 4 th ed.

SANTOS, E. M. R., 2011, Sistema combinado tratando esgoto sanitário contendo formaldeído: toxicidade remanescente avaliada em diferentes níveis tróficos. Dissertação de mestrado. Faculdade de Engenharia Civil, Arquitetura e Urbanismo, Universidade Estadual de Campinas, Campinas, SP, Brasil.

TISLER, T. \& JAGORC-KONCAN, J., 1997, Comparative assessment of toxicity of phenol, formaldehyde, and industrial wastewater to aquatic organisms. Water, Air, Soil Pollution 3-4, 315-322. http://dx.doi.org/10.1007/BF02407469

WHO - World Health Organization, 1989, Environmental Health Criteria' 89 - Formaldehyde. Geneva.

ZHAO, Z., ZHANG, Z., CHENG, J., CHEN, C., GAO, S., 2011, Acute toxicity of ammonia to offspring of Daphnia magna born by pregnant individuals during chronic exposure. Research on Environmental Science/Huanjing Kexue Yanjiu, 24: 205-209.

ZAGATTO, P.A. \& BERTOLETTI, E., 2006, Ecotoxicologia aquática: princípios e aplicações. Rima, São Carlos, SP. 